\title{
GPR43 Suppresses Intestinal Tumor Growth by Modification of the Mammalian Target of Rapamycin Complex 1 Activity in Apc ${ }^{\text {Min/+ }}$ Mice
}

\author{
Lingling Kong ${ }^{a}$ Namiko Hoshi ${ }^{a}$ Yunlong Sui ${ }^{a}$ Yasutaka Yamada ${ }^{a}$ \\ Ryutaro Yoshida ${ }^{a}$ Makoto Ooi $^{\text {a }}$ Zibin Tian $^{\text {b }}$ Ikuo Kimurac, d Yuzo Kodama ${ }^{a}$ \\ ${ }^{a}$ Division of Gastroenterology, Department of Internal Medicine, Kobe University Graduate School of Medicine, \\ Kobe, Japan; 'bepartment of Gastroenterology, The Affiliated Hospital of Qingdao University, Qingdao, China; \\ 'Laboratory of Molecular Neurobiology, Graduate School of Biostudies, Kyoto University, Kyoto, Japan; ${ }^{\mathrm{d} D e p a r t m e n t}$ \\ of Applied Biological Science, Graduate School of Agriculture, Tokyo University of Agriculture and Technology, \\ Tokyo, Japan
}

\section{Highlights of the Study}

- G protein-coupled receptor 43 suppresses tumor growth in the intestinal tumor model Apc ${ }^{\mathrm{Min} /+}$ mice.

- G protein-coupled receptor 43 does not affect inflammatory cytokines and amino acid transporters expression in $\mathrm{Apc}^{\mathrm{Min} /+}$ tumors.

- G protein-coupled receptor 43 inhibits mammalian target of rapamycin complex 1 activity independent of the Akt pathway.

\section{Keywords}

G protein-coupled receptor $43 \cdot$ FFAR2 . Short-chain fatty acids $\cdot$ Colon cancer $\cdot$ Mammalian target of rapamycin

\begin{abstract}
Objective: G protein-coupled receptor 43 (GPR43), a receptor for short-chain fatty acids, plays a role in suppressing tumor growth; however, the detailed underlying mechanism needs to be comprehensively elucidated. In this study, we investigated the role of GPR43 in inhibiting tumor growth using $\mathrm{Apc}^{\mathrm{Min} /+}$, a murine model of intestinal tumors. Materials and Methods: Using GPR43 ${ }^{-/}-\mathrm{Apc}^{\mathrm{Min} /+}$ and $\mathrm{GPR} 43^{+/-}$ $\mathrm{Apc}^{\mathrm{Min} /+}$ mice, the number of tumors was analyzed at the
\end{abstract}

karger@karger.com www.karger.com/mpp

Karger $\stackrel{\text { ' }}{5}$

GOPEN ACCESS
(C) 2021 The Author(s)

Published by S. Karger AG, Basel

This is an Open Access article licensed under the Creative Commons Attribution-NonCommercial-4.0 International License (CC BY-NC) (http://www.karger.com/Services/OpenAccessLicense), applicable to the online version of the article only. Usage and distribution for commercial purposes requires written permission. end of the experimental period. Immunohistochemistry, quantitative polymerase chain reaction, and Western blotting were performed to analyze cellular proliferation and proliferation-associated signal pathways. Results: Our results revealed that GPR43 deficiency resulted in increased tumor numbers in $\mathrm{Apc}^{\mathrm{Min} /+}$ mice. Ki67 was highly expressed in GPR43 ${ }^{-/-}$mice $(p>0.05)$. Increased expression levels of proinflammatory cytokines, including interleukin- 6 and tumor necrosis factor- $a$, and amino acid transporters were not observed in GPR43-deficient mice compared to GPR43-sufficient mice. Furthermore, GPR43-deficient tumor tissues showed enhanced mammalian target of rapamycin-mediated phosphorylated ribosomal protein $\mathrm{S} 6$ kinase beta-1 $(p>$ 0.05 ) and phosphorylated eukaryotic translation initiation 
factor $4 \mathrm{E}$-binding protein 1 ( $p>0.05)$, but not Akt (protein kinase B) phosphorylation $(p=0.7088)$. Conclusion: Collectively, GPR43 affords protection against tumor growth at least partly through inhibition of the mammalian target of rapamycin complex 1 pathway. @ @ 2021 The Author(s).

Published by S. Karger AG, Basel

\section{Introduction}

Colon cancer is the third most prevalent cancer, following lung and breast cancer, and is the second leading cause of mortality worldwide [1]. Growing evidence indicates that dietary habits are strongly associated with the development of colorectal cancer, especially decreased intake of dietary fibers and increased intake of refined foods [2]. Dietary fibers are fermented by gut flora to produce short-chain fatty acids (SCFAs) such as butyrate, acetate, and propionate in the colon [2], and it has been reported that butyrate-producing microbiota can inhibit intestinal tumor development by modulating Wnt signaling through G protein-coupled receptor 43 (GPR43) [3].

GPR43 (also called FFAR2) is a receptor for SCFAs and is expressed in intestinal epithelial cells [2]. Previous studies have revealed that GPR43 plays a critical role in SCFA-induced suppression of intestinal inflammation in a mouse model, and GPR43 expression is reportedly lost in several human colon cell lines [4]. It has been suggested that GPR43 suppresses tumor growth by employing several mechanisms; for example, by altering the structure of the gut flora [5]. However, detailed underlying mechanisms, as well as other possibly involved mechanisms, remain elusive.

The Apc ${ }^{\mathrm{Min} /+}$ mice model is an animal model of intestinal adenomas that harbors a mutation in the APC gene. Eighty-five percent of human colon cancers develop through an adenoma-carcinoma sequence, and most colon cancers develop APC gene mutations [6]. Thus, $\mathrm{Apc}^{\mathrm{Min} /+}$ mice have been widely used to investigate human intestinal tumor studies. We investigated the role of GPR43 in this animal model of intestinal tumor development.

\section{Materials and Methods}

Animals and Diets

Mice were bred under specific pathogen-free conditions in the Animal Facility at the Kobe University Graduate School of Medicine. Breeding pairs of Apc $\mathrm{Min} /+$ mice (C57BL/6 background) were purchased from Jackson Laboratory (Bar Harbor, ME, USA). GPR43 homozygous (GPR43 ${ }^{-/-}$) mice (C57BL/6 background) were provided as described previously [7]. GPR43 $3^{+/-} \mathrm{Apc}^{\mathrm{Min} /+}$ mice were generated by breeding $\mathrm{Apc}^{\mathrm{Min} /+}$ mice with $\mathrm{GPR} 43^{-/-}$ mice. Both male and female littermates were used in this study. All mice were fed a CE-2 diet (CLEA Japan Inc., Meguro-ku, Japan). Mice were allowed free access to food and water ad libitum.

\section{Tumor Counts}

At 15 weeks of age, the small intestine and colon were cut open longitudinally, and the intestinal contents were removed with curved forceps. The indigo carmine dye (Daiichi-Sankyo, Chuo$\mathrm{ku}$, Japan) was used to make the detection of tiny tumors easy. The number of tumors of the entire intestine was counted manually by the same researcher, who was blinded to the experimental groups throughout the study.

\section{Immunohistochemical Staining}

All terminal ileum specimens were fixed in formalin and embedded in paraffin. Immunohistochemical staining was performed on the paraffin-embedded sections using the polymer peroxidase method. The sections were boiled in $0.01 \mathrm{M} \mathrm{pH} 6.0$ citrate buffer for $15 \mathrm{~min}$ in a microwave oven. The sections were incubated with ki67 antibodies (1:100; Cell Signaling, \#12202) overnight at $4^{\circ} \mathrm{C}$. The cells positive for ki67 staining were analyzed by 2 researchers, blinded to the experimental protocol, using ImageJ software (NIH) to confirm the consistency of obtained results.

\section{RNA Extraction and Real-Time PCR}

Tumor and nontumor tissues were removed from the small intestine, placed in RNAlater ${ }^{\mathrm{TM}}$ (Thermo Fisher Scientific, \#AM7021), and stored at $-80^{\circ} \mathrm{C}$ until use. Real-time PCR was performed according to a previously described method [8]. Relative expression levels of target genes were standardized to HPRT expression. The primers used are listed in Table 1.

\section{Western Blotting}

Tissues were harvested from mice 9-15 weeks of age. Total lysates of tumor and nontumor tissues from the small intestine were extracted. Total lysates were incubated with antibodies against $\mathrm{p}$ p70S6K (1:1,000; Cell Signaling, \#9234), p-Akt (1:2,000, Cell Signaling, \#4060S), p-4EBP1(1:1,000; Cell Signaling, \#9455), and $\beta$-actin (1:2,000, Cell Signaling, \#8457) overnight. Western blot chemiluminescent signals were captured with an ImageQuant LAS 4000 mini imager (GE Healthcare). The band intensity was measured using Image $(\mathrm{NIH})$.

\section{Statistical Analysis}

Data are presented as mean \pm standard error of the mean, analyzed by employing Student's $t$ test, using GraphPad Prism 7 (GraphPad Software Inc., San Diego, CA, USA). $p<0.05$ was considered statistically significant.

\section{Results}

\section{Loss of GPR43 Promotes Tumor Development in the}

Small Intestine and Colon

We first confirmed that GPR43 ${ }^{+/+} \mathrm{Apc}^{\mathrm{Min} /{ }^{+}}$mice and $\mathrm{GPR}_{4}{ }^{+/-} \mathrm{Apc}^{\mathrm{Min} /+}$ mice presented a similar number of intestinal tumors (shown in online suppl. Fig. 1; see www. karger.com/doi/10.1159/000518621 for all online suppl.
Kong/Hoshi/Sui/Yamada/Yoshida/Ooi/ Tian/Kimura/Kodama 


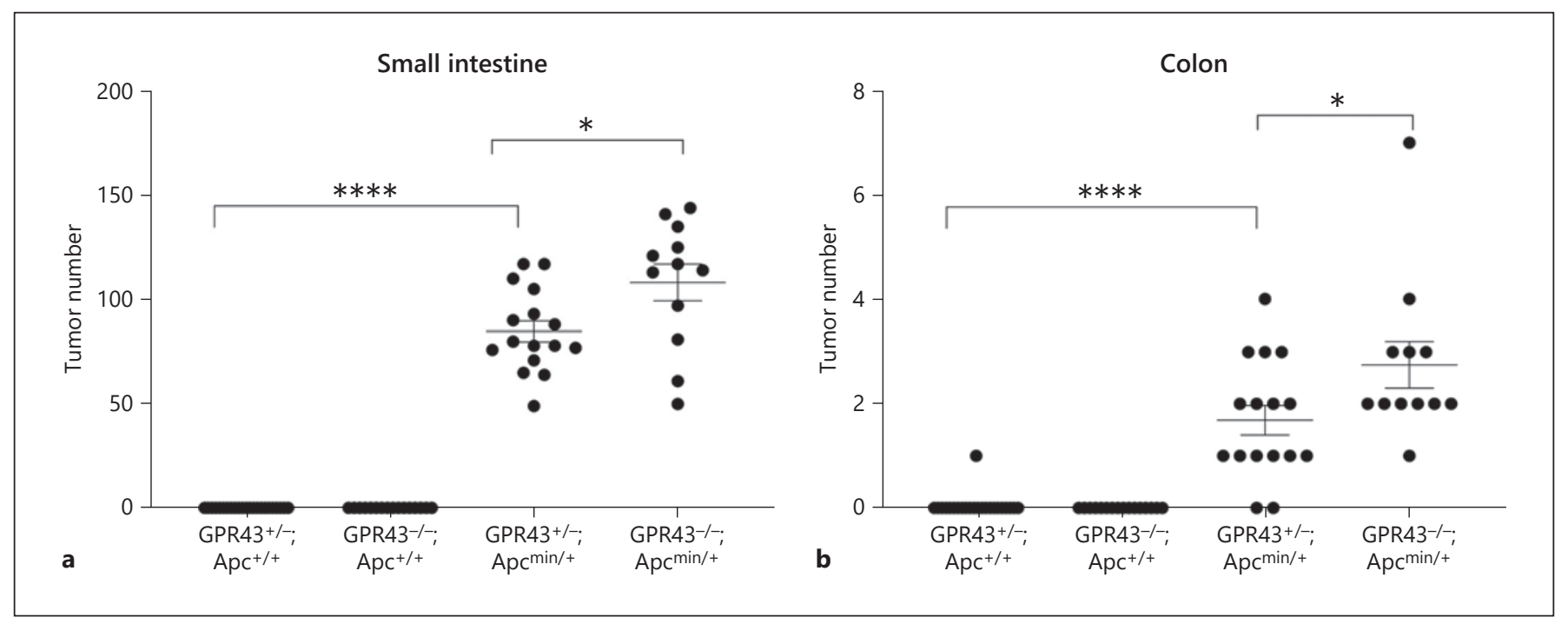

Fig. 1. GPR43 suppresses tumor growth in the mouse tumor model. Total tumor burden in the small intestine (a) and colon (b) at 15 weeks of age. GPR43 ${ }^{+/-} \mathrm{Apc}^{+/+}, n=23$; GPR43 ${ }^{-/-} \mathrm{Apc}^{+/+}, n=16$; GPR43 ${ }^{+/-} \mathrm{Apc}^{\mathrm{Min} /+}, n=$ 16; $\mathrm{GPR}_{43}{ }^{-/-} \mathrm{Apc}^{\mathrm{Min} /+}, n=12$. Statistical analysis was performed using Student's $t$ test. ${ }^{*} p<0.05,{ }^{* * * *} p<0.0001$.

Table 1. The primers used for real-time PCR in this study

\begin{tabular}{lll}
\hline Gene & Forward $\left(5^{\prime}-3^{\prime}\right)$ & Reverse $\left(5^{\prime}-3^{\prime}\right)$ \\
\hline IL-6 & GACAAAGCCAGAGTCCTTCAGAGAGATACAG & TTGGATGGTCTTGGTCCTAGCCAC \\
TNF-a & AAAATTCGAGTGACAAGCCTGTAG & CCCTTGAAGAGAACCTGGGAGTAG \\
LTA1 & CTGGATCGAGCTGCTCATC & GTTCACAGCTGTGAGGAGC \\
ASCT2 & CGGCACGCCCGGGAGCTTC & GAATCTGGGGGCGGAAGCGG \\
HPRT & GTTGGATACAGGCCAGACTTTTTG & CCAGTTCACTGGTGACACAAACG
\end{tabular}

material), indicating that heterozygous GPR43 expression does not affect the number of intestinal tumors observed in the $\mathrm{Apc}^{\mathrm{Min} /+}$ mouse strain. To further determine the GPR43 function, we used GPR43 ${ }^{+/-} \mathrm{Apc}^{\mathrm{Min} /+}$ and $\mathrm{GPR}_{4} 3^{-/-} \mathrm{Apc}^{\mathrm{Min} /+}$ littermate mice for comparison. Expression of GPR43 was evaluated by real-time PCR, confirming that the genotyping result was reliable (shown in online suppl. Fig. 2). At 15 weeks of age, the GPR $43^{-/-}$ $\mathrm{Apc}^{\mathrm{Min} /+}$ mice showed a higher number of tumors than $\mathrm{GPR} 3^{+/-} \mathrm{Apc}^{\mathrm{Min} /+}$ mice (shown in Fig. 1a, b), suggesting that GPR43 plays an important role in suppressing intestinal tumor development. Ki67, a marker of proliferation in tumor tissues, was enhanced in GPR $43^{-/-} \mathrm{Apc}^{\mathrm{Min} /+}$ mice. Increased cell proliferation and suppression of apoptosis are important factors that promote tumor growth [9]. To investigate how GPR43 deficiency results in increased numbers of tumor, we performed immunohistochemistry to measure expression levels of ki67 in tumor tissues obtained from both $\mathrm{GPR}_{4} 3^{+/-} \mathrm{Apc}^{\mathrm{Min} /+}$ and $\mathrm{GPR}_{43}{ }^{-/-} \mathrm{Apc}^{\mathrm{Min} /+}$ mice. The results showed that the $\mathrm{GPR} 3^{-/-} \mathrm{Apc}^{\mathrm{Min} /+}$ tumor tissues exhibited higher levels of ki67-positive cells (shown in Fig. 2a, b). Conversely, TUNEL staining, performed to compare the frequency of apoptotic tumor cells, revealed infrequent positive cells in both groups (data not shown). These results suggest that GPR43 deficiency may promote cell proliferation in $\mathrm{Apc}^{\mathrm{Min} /+}$ mice.

\section{GPR43 Deficiency Enhances the mTORC1 Pathway}

It is well known that inflammation is associated with tumor growth. Reportedly, the overexpression of interleukin (IL) -6 promotes cachexia and increases intestinal tumors in $\mathrm{Apc}^{\mathrm{Min} /+}$ mice [10], and blocking tumor necrosis factor (TNF)-ain mice decreases colorectal carcinogenesis [11]. Therefore, we assessed the expression of TNF- $\alpha$ and IL- 6 in $\mathrm{GPR}_{4} 3^{+/-} \mathrm{Apc}^{\mathrm{Min} /+}$ and $\mathrm{GPR}_{4} 3^{-/-} \mathrm{Apc}^{\mathrm{Min} /+}$ mice by real- 


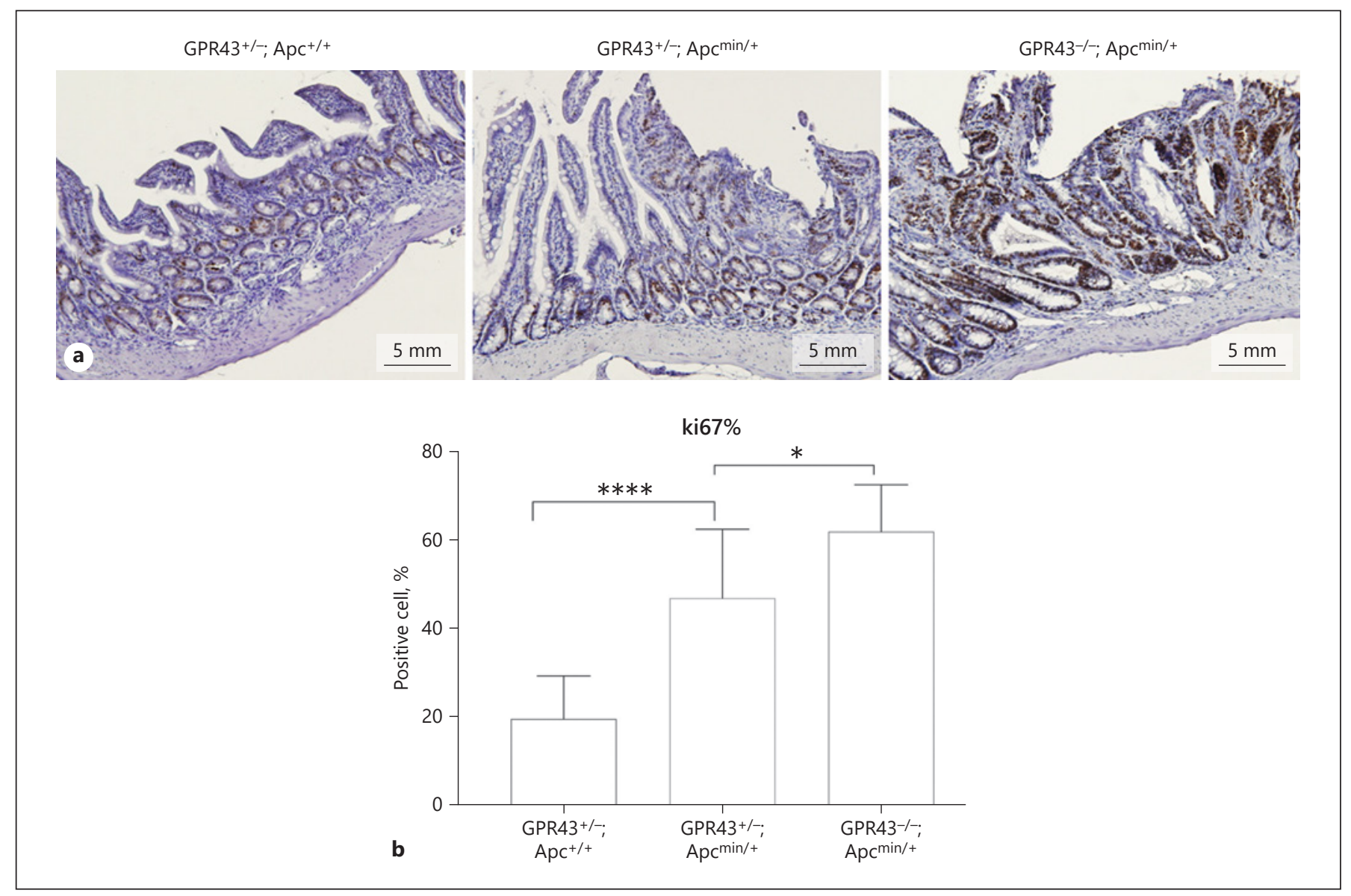

Fig. 2. GPR43 deficiency promotes cell proliferation in $\mathrm{Apc}^{\mathrm{Min} /+}$ mice. a Representative picture of staining analysis. b Staining of proliferative marker (ki67) was enhanced in GPR43-/- $\mathrm{Apc}^{\mathrm{Min} /+}$ mice. The ki67-positive cells in each group were assessed using ImageJ. GPR $43^{+/-} \mathrm{Apc}^{+/+}, n=10$; $\mathrm{GPR}^{2} 3^{+/-} \mathrm{Apc}^{\mathrm{Min} /+}, n=14, \mathrm{GPR} 43^{-/-}$ $\mathrm{Apc}^{\mathrm{Min} /+}, n=7$. Scale bar, $5.0 \mathrm{~mm}$. Magnification, $\times 200$. Statistical analysis was performed using Student's $t$ test. ${ }^{*} p<0.05,{ }^{* * * *} p<0.0001$.

time PCR; however, the expression of both inflammatory genes did not demonstrate any difference (Fig. 3a, b). This suggests that in our current setting, GPR43 affords protection against tumor development not through the modulation of the inflammatory pathway. Furthermore, tumor cells require a large number of nutrients and amino acids for rapid cell proliferation [12]. Both L-type amino acid transporter (LAT1) and ASCT2 are important amino acid transporters, and knockdown of LAT1 and ASCT2 with RNA interference exhibits reduced cell proliferation [13]. We speculated whether GPR43 deficiency can modulate the expression of amino acid transporters. $\mathrm{Apc}^{\mathrm{Min} /+}$ tumors demonstrated higher expression levels of these transporters than $\mathrm{Apc}^{+/+}$intestinal tissue; however, no difference was observed between GPR $43^{+/-} \mathrm{Apc}^{\mathrm{Min} /+}$ and $\mathrm{GPR} 43^{-/-}$
$\mathrm{Apc}^{\mathrm{Min} /+}$ tissues (shown in Fig. 3c, d). The mammalian target of rapamycin complex 1 (mTORC1) pathway plays an extremely important role in cell proliferation. It promotes cell growth by promoting protein translation, as well as ribosome biogenesis, and the prototypic mTOR pathway is activated by the PI3K/Akt pathway; however, it can receive multiple signal inputs in an Akt-independent manner [14]. Protein kinase S6k1 and 4EBP1 are downstream of the mTORC1 pathway and are activated by phosphorylation. We hypothesized that GPR43 deficiency enhances the mTORC1 pathway. As expected, Western blotting revealed enhanced phosphorylation of p70S6K (p-p70S6K) and 4EBP1 (p-4EBP1) in GPR43 ${ }^{-/-} \mathrm{Apc}^{\mathrm{Min} /+}$ mice, but interestingly, phospho-Akt (p-Akt) enhancement was not observed (shown in Fig. 4a, b).
42

Med Princ Pract 2022;31:39-46 DOI: $10.1159 / 000518621$
Kong/Hoshi/Sui/Yamada/Yoshida/Ooi/ Tian/Kimura/Kodama 


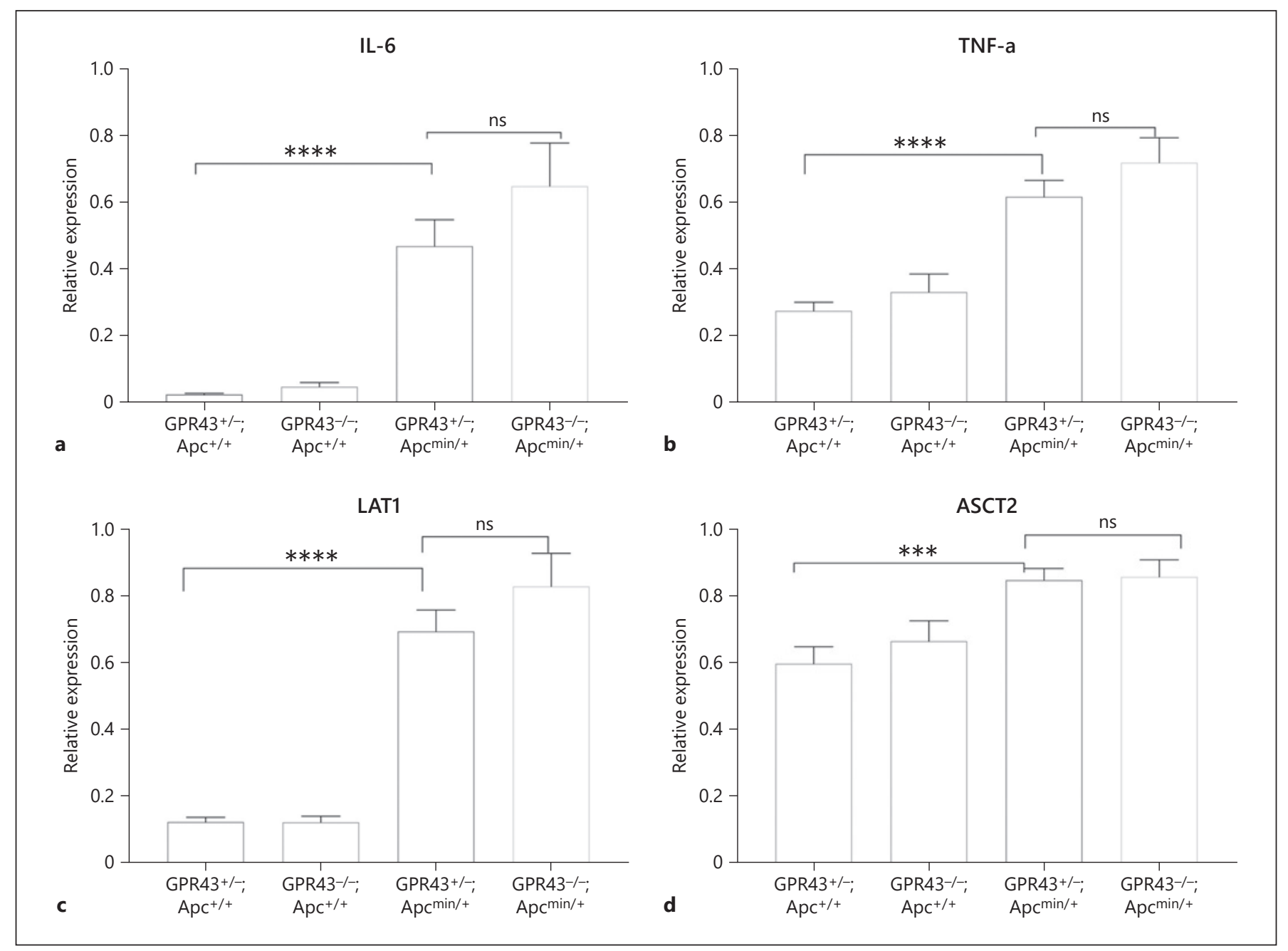

Fig. 3. Real-time PCR analysis does not reveal any difference in the small intestine. Normal tissues were harvested from GPR43 $3^{+/-} \mathrm{Apc}^{+/+}(n=20)$ and GPR43 ${ }^{-/-} \mathrm{Apc}^{+/+}$mice $(n=14)$; tumor tissues were harvested from GPR43 $3^{+/-}$ $\mathrm{Apc}^{\mathrm{Min} /+}(n=16)$ and GPR43 ${ }^{-/-} \mathrm{Apc}^{\mathrm{Min} /+}$ mice $(n=12)$. All tissues were harvested from the small intestine. a-d Gene expression levels were analyzed. Data are presented as mean \pm standard error of the mean. ${ }^{* * *} p<0.0005$, $* * * * p<0.0001$, ns, no significance, $p>0.05$. Statistical analysis was performed using Student's $t$ test.

\section{Discussion}

GPR43 is mainly expressed in intestinal epithelial cells, and GPR43 is also expressed in the small intestine of $\mathrm{Apc}^{\mathrm{Min} /+}$ mice. It has been reported that GPR43 deficiency enhances the downstream signals of the cAMP-PKACREB pathway, leading to histone deacetylase overexpression [15]. It has also been shown that the butyrateproducing probiotic called Clostridium butyricum could inhibit high-fat diet induced intestinal tumor development in Apc ${ }^{\mathrm{Min} /+}$ mice through GPR43 [3]. These observations indicate the importance of the interactions between gut flora, SCFAs, and GPR43 in the intestinal tumor de- velopment. However, to the best of our knowledge, the possible modification of mTORC1 activation by GPR 43 in the intestinal tumor has not been previously reported.

Chronic inflammation is linked to tumorigenesis, including cell survival and proliferation [16]. GPR43-/mice reportedly exhibit severe inflammation in a mouse model of dextran sulfate sodium colitis. Nuclear factor$\mathrm{kB}$ regulates numerous genes involved in inflammatory responses in activated M1 macrophages, including IL-6 and TNF- $\alpha$ [17], both of which are highly expressed in tumors. However, our results failed to demonstrate any increased expression of IL- 6 and TNF- $\alpha$ in the GPR43deficient tissue, indicating that the increased tumor phe- 


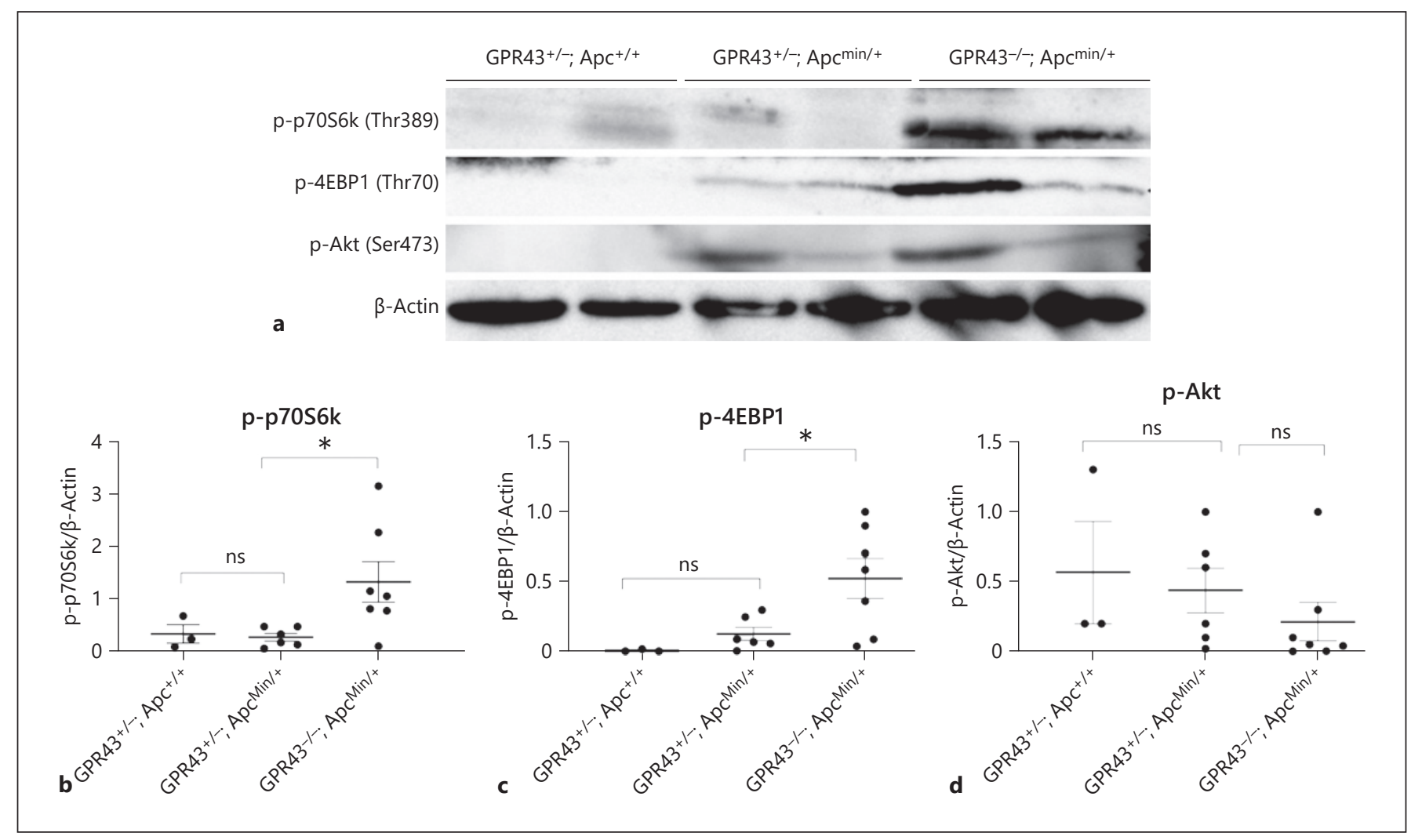

Fig. 4. GPR43 deficiency enhanced the mTORC1 pathway independent of the Akt signaling pathway. Total lysates of tumor or nontumor tissues from the small intestine were extracted. Representative picture of Western blotting analysis (a) and the band intensity of p-p70S6K (b), p-4EBP1 (c), and p-Akt (d) in each group are shown. $\mathrm{GPR}_{3}{ }^{+/-} \mathrm{Apc}^{+/+}, n=3$; GPR43 ${ }^{+/-} \mathrm{Apc}^{\mathrm{Min} /+}, n=6$; $\mathrm{GPR}_{3}{ }^{-/-} \mathrm{Apc}^{\mathrm{Min} /+}, n=7$. Statistical analysis was performed using Student's $t$ test. ns, no significance, ${ }^{*} p<0.05$.

notype was not due to aberrant immunological activation. SCFAs, such as butyrate, are known to fuel intestinal epithelial cell growth [18], and hence we speculated whether GPR43 deficiency might upregulate some genes to take-up alternative nutrients such as amino acids. Cancer progression is linked to increased nutrient uptake to support cellular proliferation [19]. Among over 60 amino acid transporters, LAT1 and ASCT2 are major pro-tumoral transporters with high-level expression in several cancer types, including colon cancer, and the knockdown of both amino acid transporters can suppress cell growth [12]. However, unfortunately, similar levels of LAT1 and ASCT2 expression can be detected in both GPR $43^{+/-}$ $\mathrm{Apc}^{\mathrm{Min} /+}$ and $\mathrm{GPR}_{4} 3^{-/-} \mathrm{Apc}^{\mathrm{Min} /+}$ mice, indicating that the increased tumor proliferation is possibly not associated with increased amino acid transporter expression.

mTORC1 is critical for the proliferation of Apc-deficient mice [13]; however, the interconnection between GPR43 and the mTORC1 pathway has not yet been inves- tigated. Signaling associated with the mTORC1 pathway has been intensively studied, and the classical mechanism of mTORC1 regulation through the Akt pathway activation is widely known. Conversely, mTORC1 can also be activated in an Akt-independent pathway. In the current study, we observed that the expression of p-p70S6K and $\mathrm{p}-4 \mathrm{EBP} 1$ was stronger in GPR43 ${ }^{-/-} \mathrm{Apc}^{\mathrm{Min} /+}$ mice, suggesting that GPR43 deficiency induces mTORC1 pathway activation to promote cell proliferation in $\mathrm{Apc}^{\mathrm{Min} /+}$ mice.

Interestingly, our results indicate that GPR43 deficiency does not affect Akt phosphorylation. Akt-independent mechanisms of mTOR regulation have been reported in several studies, and researchers have revealed that the Ras/ MEK/ERK pathway may also activate mTOR via phosphorylation of tuberous sclerosis complex 2 (TSC2). TSC is a genetic disorder characterized by numerous benign tumors, and patients with TSC frequently show extracellular signal-regulated kinase activation [20]. Furthermore, the mTOR pathway is regulated by energy-sensing pathways,
44

Med Princ Pract 2022;31:39-46 DOI: $10.1159 / 000518621$
Kong/Hoshi/Sui/Yamada/Yoshida/Ooi/ Tian/Kimura/Kodama 
with intracellular energy depletion suppressing mTOR activation through regulation of AMP-activated protein kinase, which is activated by calmodulin-dependent protein kinase $\beta$, associated with increased intracellular calcium. Additionally, the binding of hormones and cytokines to Gq-couple receptors activate AMP-activated protein kinase [21]. Moreover, a previous study has reported that the mTORC1 pathway remains active even following complete inhibition of the PI3K/Akt pathway in a breast cancer cell line [22]. In addition to the above findings, mTORC1 couples with amino acids to regulate cell proliferation [23]. However, the involvement of amino acids, especially that of transporters, appeared contradictory in our study.

Although our results showed that GPR43 deficiency led to the enhancement of the MTORC1 pathway without affecting phosphorylation of Akt, the direct evidence of the interaction between those is missing in this study. We only tested expression levels of very limited number of major amino acid transports with negative findings in the current study; however, a lot more transporters exist. The interactions between GPR43 and mTORC1 pathway might be far more complicated, and GPR43 might be inhibiting the WNT pathway and indirectly influencing mTORC1 activation. Comprehensive analysis such as RNA sequencing data using tumor tissues from GPR43deficient and -sufficient mice might be one good way to investigate it further as a future study.

\section{Conclusion}

We observed that the expression of p-p70S6K and p4EBP1 was enhanced in GPR $43^{-/-} \mathrm{Apc}^{\mathrm{Min} /+}$ mice, but not p-Akt. This may suggest that GPR43 inhibits tumor de- velopment partly by suppressing the mTORC1 pathway independent of the Akt pathway. The exact mechanism of GPR43 in regulating the mTORC1 pathway in $\mathrm{Apc}^{\mathrm{Min} /+}$ mice warrants further investigation.

\section{Statement of Ethics}

All animal experiments were approved by the Institutional Animal Care and Use Committee of Kobe University (Permission No. P160505).

\section{Conflict of Interest Statement}

The authors declare that they have no conflicts of interest.

\section{Funding Sources}

This study was funded by the Japan Society for the Promotion of Science KAKENHI Grant (Grant No. JP70448174 and JP40645214).

\section{Author Contributions}

L.K. and N.H. conceived and designed the experiments. L.K., N.H., Y.S., Y.Y., R.Y., M.O., Z.T., I.K., and Y.K. analyzed the data and drafted the manuscript.

\section{Data Availability Statement}

The authors confirm that the data supporting the findings of this study are available within the article and its supplementary materials.

\section{References}

1 Wong KE, Ngai SC, Chan KG, Lee LH, Goh $\mathrm{BH}$, Chuah LH. Curcumin nanoformulations for colorectal cancer: a review. Front Pharmacol. 2019 Mar; 10:152.

2 Sivaprakasam S, Prasad PD, Singh N. Benefits of short-chain fatty acids and their receptors in inflammation and carcinogenesis. Pharmacol Ther. 2016 Aug; 164:144-51.

3 Chen D, Jin D, Huang S, Wu J, Xu M, Liu T, et al. Clostridium butyricum, a butyrate-producing probiotic, inhibits intestinal tumor development through modulating Wnt signaling and gut microbiota. Cancer Lett. 2020 Jan;469:456-67.

4 Tang Y, Chen Y, Jiang H, Robbins GT, Nie D. G-protein-coupled receptor for short-chain fatty acids suppresses colon cancer. Int $J$ Cancer. 2011 Feb 15;128(4):847-56.

5 Sivaprakasam S, Gurav A, Paschall AV, Coe GL, Chaudhary K, Cai Y, et al. An essential role of FFAR2 (GPR43) in dietary fibre-mediated promotion of healthy composition of gut microbiota and suppression of intestinal carcinogenesis. Oncogenesis. 2016 Jun 27;5(6): e238.

6 Morin PJ, Sparks AB, Korinek V, Barker N, Clevers H, Vogelstein B, et al. Activation of beta-catenin-Tcf signaling in colon cancer by mutations in beta-catenin or APC. Science. 1997 Mar 21;275(5307):1787-90.

7 Kimura I, Ozawa K, Inoue D, Imamura T, Kimura K, Maeda T, et al. The gut microbiota suppresses insulin-mediated fat accumulation via the short-chain fatty acid receptor GPR43. Nat Commun. 2013;4:1829.

8 Adachi S, Hoshi N, Inoue J, Yasutomi E, Otsuka $\mathrm{T}$, Dhakhwa $\mathrm{R}$, et al. Indigo naturalis ameliorates oxazolone-induced dermatitis but aggravates colitis by changing the composition of gut microflora. Int Arch Allergy Immunol. 2017;173(1):23-33.

9 Zheng Q, Li Y, Zhang D, Cui X, Dai K, Yang $Y$, et al. ANP promotes proliferation and inhibits apoptosis of ovarian granulosa cells by NPRA/PGRMC1/EGFR complex and improves ovary functions of PCOS rats. Cell Death Dis. 2017 Oct 26;8(10): e3145. 
10 Kitamura H, Ohno Y, Toyoshima Y, Ohtake J, Homma S, Kawamura H, et al. Interleukin-6/STAT3 signaling as a promising target to improve the efficacy of cancer immunotherapy. Cancer Sci. 2017 Oct;108(10):194752.

11 Popivanova BK, Kitamura K, Wu Y, Kondo T, Kagaya T, Kaneko S, et al. Blocking TNF-alpha in mice reduces colorectal carcinogenesis associated with chronic colitis. J Clin Invest. 2008 Feb;118(2):560-70.

12 Kong FL, Yang DJ. Amino acid transportertargeted radiotracers for molecular imaging in oncology. Curr Med Chem. 2012;19(20): 3271-81.

13 Liang Z, Cho HT, Williams L, Zhu A, Liang $\mathrm{K}$, Huang $\mathrm{K}$, et al. Potential biomarker of Ltype amino acid transporter 1 in breast cancer progression. Nucl Med Mol Imaging. 2011 Jun;45(2):93-102.

14 Zoncu R, Efeyan A, Sabatini DM. mTOR: from growth signal integration to cancer, diabetes and ageing. Nat Rev Mol Cell Biol. 2011 Jan;12(1):21-35.
15 Pan P, W Skaer C, Wang HT, Oshima K, Huang YW, Yu J, et al. Loss of free fatty acid receptor 2 enhances colonic adenoma development and reduces the chemopreventive effects of black raspberries in ApcMin/+ mice. Carcinogenesis. 2017 Jan;38(1):86-93.

16 Mantovani A. Cancer: inflammation by remote control. Nature. 2005 Jun 9;435(7043): $752-3$.

17 Liu T, Zhang L, Joo D, Sun SC. NF- $\kappa B$ signaling in inflammation. Signal Transduct Target Ther. 2017;2:17023.

18 Parada Venegas D, De la Fuente MK, Landskron G, González MJ, Quera R, Dijkstra G, et al. Short chain fatty acids (SCFAs)-mediated gut epithelial and immune regulation and its relevance for inflammatory bowel diseases. Front Immunol. 2019 Mar 11;10:277.

19 Salisbury TB, Arthur S. The regulation and function of the L-type amino acid transporter 1 (LAT1) in cancer. Int J Mol Sci. 2018 Aug $12 ; 19(8): 2373$.
20 Han S, Santos TM, Puga A, Roy J, Thiele EA, McCollin M, et al. Phosphorylation of tuberin as a novel mechanism for somatic inactivation of the tuberous sclerosis complex proteins in brain lesions. Cancer Res. 2004 Feb 1; 64(3):812-6.

21 Kishi K, Yuasa T, Minami A, Yamada M, Hagi A, Hayashi $\mathrm{H}$, et al. AMP-activated protein kinase is activated by the stimulations of G(q)-coupled receptors. Biochem Biophys Res Commun. 2000 Sep 16;276(1):16-22.

22 Castel P, Ellis H, Bago R, Toska E, Razavi P, Carmona FJ, et al. PDK1-SGK1 signaling sustains AKT-independent mTORC1 activation and confers resistance to PI3Ka inhibition. Cancer Cell. 2016 Aug 8;30(2):229-42.

23 Swiatkowski P, Nikolaeva I, Kumar G, Zucco A, Akum BF, Patel MV, et al. Role of Akt-independent $\mathrm{mTORC} 1$ and GSK $3 \beta$ signaling in sublethal NMDA-induced injury and the recovery of neuronal electrophysiology and survival. Sci Rep. 2017 May 8;7(1):1539. 